\title{
Position-dependent trunk asymmetry assessed with scoliometer
}

\author{
J Chowańska ${ }^{1 *}$, T Kotwicki $^{2}$, K Rosadziński $^{2}$ \\ From 8th International Conference on Conservative Management of Spinal Deformities and SOSORT 2011 \\ Annual Meeting \\ Barcelona, Spain. 19-21 May 2011
}

\section{Purpose of the study}

It was to assess the influence of child positioning during examination with Bunnell scoliometer on value of angle of trunk inclination.

\section{Background}

During school screening for scoliosis the Angle of Trunk Inclination/Rotation (ATI/ATR) measurement is performed with the use of scoliometer. Early adolescent girls are the target group for scoliosis screening. Further evaluation is recommended when ATI is equal or above $7^{\circ}$. Standing forward bending position is a standard one, however sitting position is also advocated [1-7].

\section{Materials and methods}

The study comprised 996 girls, aged 9 to 13, mean $11.0 \pm$ 1.0 years of age. ATI measurements were performed at three levels of the spine: proximal thoracic, main thoracic and thoracolumbar/lumbar. Maximal ATI values for standing and sitting forward bending positions were noted. Based on the ' 7 ' criterion, the number of children who need follow up was revealed, according to position: (a) standing, (b) sitting, (c) any of standing or sitting, (d) either standing or sitting.

\section{Results}

On each level of the spine the ATI value was lower for the sitting forward-bending position than for the standing one. The prevalence of Bunnell $\geq 7^{\circ}$ was as follows: (a) $3.9 \%$, (b) $3.2 \%$, (c) $4.5 \%$ and (d) $2.4 \%$.

\section{Conclusions}

The value of ATI depends on body position during scoliometer measurement. Sitting position can be considered for the purpose of school screening for scoliosis, alone or as complement of the standing one.

\section{Author details \\ ${ }^{1}$ Rehasport Clinic, Poznań, Poland; Spine Disorders Unit, Department of Pediatric Orthopedics and Traumatology, University of Medical Sciences, Poznan, Poland. ${ }^{2}$ Spine Disorders Unit, Department of Pediatric Orthopedics and Traumatology, University of Medical Sciences, Poznan, Poland.}

Published: 27 January 2012

\section{References}

1. Bunnell WP: An objective criterion for scoliosis screening. J Bone Joint Surg 1984, 66:1381-1387.

2. Bunnell WP: Outcome of spinal screening. Spine 1993, 18:1572-1580.

3. Bunnell WP: Selective screening for scoliosis. Clinical Orthopaedics and Related Research 2005, 434:40-45.

4. Grivas TB, Vasiliadis ES, Koufopoulos G, Segos D, Triantafyllopoulos G, Mouzakis $\mathrm{V}$ : Study of trunk asymmetry in normal children and adolescents. Scoliosis 2006, 1:19.

5. Kotwicki T, Chowańska J, Kinel E, Lorkowska M, StryŁa W, Szulc A: Sitting forward bending position versus standing position for studying the back shape in scoliotic children. Scoliosis 2007, 2:S34.

6. Kotwicki T, Lorkowska M, Szulc A: Analiza zmienności kąta rotacji tułowia w zależności od pozycji badania u dzieci ze skoliozą idiopatyczną. Annales Academiae Medicae Silesiensis 2007, 61(1):1-6.

7. Upadhyay SS, Burwell RG, Webb JK: Hump changes on forward flexion of the lumbar spine in patients with idiopathic scoliosis. A study using ISIS and the Scoliometer in two standard positions. Spine 1988, 13:146-151.

doi:10.1186/1748-7161-7-S1-060

Cite this article as: Chowańska et al:: Position-dependent trunk asymmetry assessed with scoliometer. Scoliosis 2012 7(Suppl 1):060. 